\title{
Assessment of Overweight and Obesity Prevalence Among Practicing Nurses and Midwives in the Hohoe Municipality of the Volta Region, Ghana
}

\author{
Charles Duodu $^{1,2, *}$, Thomas Kwasi Awuni ${ }^{1,3}$, Prosper Attito ${ }^{1,4}$, Francis Bruno Zotor ${ }^{1}$ \\ ${ }^{1}$ Department of Family and Community Health, School of Public Health, University of Health and Allied Sciences, Ho, Volta region, Ghana \\ ${ }^{2}$ Ghana Health Service, Volta Regional Health Directorate, Ho, Volta region, Ghana \\ ${ }^{3}$ Ghana Health Service, Agona East District Health Directorate, Agona-Nsaba, Central region, Ghana \\ ${ }^{4}$ Ghana Health Service, North Dayi District Health Directorate, Anfoega, Volta region, Ghana
}

\section{Email address:}

duoducharles@yahoo.com (C. Duodu)

\section{To cite this article:}

Charles Duodu, Thomas Kwasi Awuni, Prosper Attito, Francis Bruno Zotor. Assessment of Overweight and Obesity Prevalence Among Practicing Nurses and Midwives in the Hohoe Municipality of the Volta Region, Ghana. Science Journal of Public Health.

Vol. 3, No. 6, 2015, pp. 842-851. doi: 10.11648/j.sjph.20150306.18

\begin{abstract}
Overweight and obesity describe an abnormal or excessive fat accumulation in the body that may impair health. They are associated with a greater risk of disability and premature death due to type 2 diabetes mellitus (T2DM) and cardiovascular diseases (CVD) such as hypertension, stroke and coronary heart disease. Prevalence of overweight and obesity is increasing in various populations, and is becoming a huge problem among occupational or professional groups that are perceived as sedentary. The main objective of the study was to assess the prevalence and potential determinants of overweight and obesity among practicing nurses and midwives in the Hohoe Municipality of the Volta Region of Ghana. A cross-sectional analytical design was employed in this study, conducted from May to June 2015. One hundred and thirty five ( $\mathrm{n}=135)$ eligible practicing nurses and midwives were selected using multi-stage sampling method based on probability proportionate to size (PPS). Anthropometric instruments were used to collect data such as weight, height, waist and hip circumferences; lifestyle and dietary habits; knowledge and perception of respondents on overweight and obesity were also collected. The data were entered and analysed statistically using SPSS, version 20. The ages of respondents ranged from 21 to 62 years with a mean age of 36.0 (SD 12.6) years old $(\chi 2=10.4, P=.02)$. In terms of sex, $80.7 \%$ of respondents were females whereas $19.3 \%$ were males. Of all the respondents, $43.7 \%$ were married $\left(\chi^{2}=2.9, P=.41\right), 96.3 \%$ were Christians $(\chi 2=12.3, P<.001)$ and $77.8 \%$ were of the Ewe ethnic group $(\chi 2=11.5, P=.04)$. The categories of the respondents were made up of $77.8 \%$ nurses and $22.2 \%$ midwives (Fisher's exact $=.001)$. Using the WHO criteria for Body Mass Index $(B M I)$, the prevalence of overweight among respondents was $31.8 \%$ (6.7\% males and $25.1 \%$ females) whereas $28.9 \%$ comprising only females were obese. Mean BMI of respondents was $27.2($ SD 5.5$) \mathrm{kg} / \mathrm{m}^{2}$. Physical inactivity (Fisher's exact $=18.65, P<.001$ ) and dietary habits such as eating late in the night $(P<.010)$ were found in this study to be contributory factors to overweight and obesity. In total, $60.7 \%$ of respondents sampled were either overweight or obese. We suggest that health managers should pay special attention to nurses and midwives regarding prevention and control of overweight and obesity in order to curb serious implications on their health and productivity.
\end{abstract}

Keywords: Prevalence, Overweight, Obesity, Nurse, Midwife, Hohoe Municipality

\section{Introduction}

The World Health Organization (WHO) defines overweight and obesity respectively as a Body Mass Index (BMI) greater than or equal to $25 \mathrm{~kg} / \mathrm{m}^{2}$ and BMI greater than or equal to $30 \mathrm{~kg} / \mathrm{m}^{2}$. Overweight and obesity also refer to an abnormal or excessive fat accumulation in the body that presents a risk to an individual's health. Overweight and obesity constitute major risk factors for a number of chronic diseases, including cardiovascular diseases (such as high blood pressure and stroke), type 2 diabetes, some cancers, asthma, arthritis and various other physical, psychological, and social morbidities as well as depression, discrimination 
and weight-related bias. Some factors contributing to the development of obesity include genetic background, different social and environmental factors such as sedentary lifestyle and unhealthy dietary habits [1-2].

Globally, the proportion of adults with a BMI of $25 \mathrm{~kg} / \mathrm{m}^{2}$ or greater increased between 1980 and 2013 from $28 \cdot 8 \%$ to $36 \cdot 9 \%$ in men, and from $29 \cdot 8 \%$ to $38.0 \%$ in women [3]. Specifically, in 2010 , overweight and obesity were estimated to cause 3.4 million deaths, $4 \%$ of years of life lost, and $4 \%$ of disabilityadjusted life-years (DALYs) worldwide. It has also been estimated that by 2025, three quarters of the obese population worldwide will be in non-industrialized countries [2].

Although the problem of obesity and overweight was once an issue only in high income countries, its prevalence has now drastically risen in low- and middle-income countries that are now facing a "double burden" of disease [4]. The factors that may account for the growing global epidemic of overweight and obesity include genetics and social factors such as socio-economic status, race/ethnicity, media and marketing, and the physical environment, which influences energy consumption and expenditure [5].

Physical inactivity and increased sedentary nature of daily activities have become serious threats to the body as they increase the risk of overweight and obesity, which may be harmful to normal body function and job productivity. Technological advancements in the sciences have simplified life and work for many professionals (including health professionals) bringing about a reduction in physical activity levels for many individuals in such professions. The result of a reduction in energy expenditure may have implications for overweight and obesity if individuals are exposed to such conditions over a long period as revealed in other studies elsewhere [6].

A systematic review on prevalence of overweight and obesity in adult Nigerians showed that in Nigeria, the prevalence of overweight individuals ranged from $20.3 \%$ $35.1 \%$, while the prevalence of obesity ranged from $8.1 \%$ $22.2 \%$ [7]. Studies in Nigeria and the United States of America have revealed high prevalence of overweight and obesity among nurses (62.2\% and 54\% respectively) [6,8]. In Ghana, the Demographic and Health Survey (DHS), based on nationally representative data, reported $30 \%$ overweight (including 9\% obesity) among 15-49 year old Ghanaian women [9]. A cross-sectional study on overweight and hypertension among college of health sciences employees in the University of Ghana revealed that $43 \%$ of respondents were overweight, including $13 \%$ who were obese [10]. Findings from a study in Ghana also revealed that the prevalence of overweight and obesity among nurses were $26.4 \%$ and $16.9 \%$ respectively [11]. Concern about the health risks associated with rising obesity has become nearly universal with global call for regular monitoring of changes in the prevalence of overweight and obesity in all populations [12]. In spite of the above findings elsewhere, there is no information of this nature among practicing nurses and midwives in the Hohoe Municipality of the Volta region of Ghana to inform management decision making in the prevention and control of overweight and obesity among this sub-group. It is therefore, necessary to assess the prevalence and potential determinants of overweight and obesity among these groups of health professionals as this would serve as a source of information for quality assurance and health policy planning in the prevention, control and management of overweight and obesity.

\section{Materials and Methods}

A cross-sectional analytical design was used in this study. The study was conducted from May to June 2015 in the Hohoe Municipality of the Volta region of Ghana. Respondents were selected from public health facilities in all the seven sub-municipalities; Hohoe, Agumatsa, Gbi-rural, Alavanyo, Lolobi, Likpe and Akpafu-Santrokofi using multistage sampling method based on probability proportionate to size (PPS). One hundred and thirty five $(n=135)$ eligible practicing nurses and midwives were selected for study. Respondents included in the study were 18 years and above, non-pregnant (females only) who consented to participate. A modified structured questionnaire from previously validated questionnaire consisting of open and closed-ended questions was used to collect background characteristics, knowledge, perception, lifestyle and anthropometric data from respondents. Anthropometric instruments used in the study were, stadiometer (model: Seca 217), non-elastic measuring tape and Standardized Stunkard Figure Rating Scale (SFRS).

\subsection{Anthropometric Measurements}

Overweight and obesity were assessed using three measures which were body mass index (BMI), waist circumference (WC), and waist-to-hip ratio (WHR). Trained data collectors obtained anthropometric measurements at the time of survey administration with participants wearing lightweight clothing without shoes or sandals. Height (m) was measured with a Stadiometer (model: Seca 217), to the nearest $0.01 \mathrm{~cm}$ with participants standing upright. Weight was measured using electronic bathroom weighing scale (model: BedNBath - BB-3018A) to the nearest $0.1 \mathrm{~kg}$. BMI was calculated as weight $(\mathrm{kg})$ divided by height squared $\left(\mathrm{m}^{2}\right)$, and BMI categories were defined following the WHO standard as $<18.5 \mathrm{~kg} / \mathrm{m}^{2}=$ underweight, $18.5-24.9 \mathrm{~kg} / \mathrm{m}^{2}=$ normal weight, $25.0-29.9 \mathrm{~kg} / \mathrm{m}^{2}=$ overweight, and $>30 \mathrm{~kg} / \mathrm{m}^{2}$ $=$ obese. WC was measured with a non-elastic measuring tape at an eye level to the nearest $0.1 \mathrm{~cm}$ in a horizontal plane around the abdomen at the level of the iliac crest (widest girth) to the nearest $0.1 \mathrm{~cm}$. Hip circumference (HC) was measured with a non-elastic measuring tape at the level of the greater trochanter (maximum circumference) to the nearest $0.1 \mathrm{~cm}$. Waist -to- hip ratio was calculated by dividing $\mathrm{WC}$ by HC. WHR and WC are used as indirect measures of abdominal obesity, and fat distributions around the waist are associated with greater risk for metabolic and cardiovascular disease [13]. WC and WHR are better predictors of obesity in the elderly than BMI due to differential muscle loss associated with aging [14]. Recommended by the National 
Institutes of Health, cut-off points for obesity defined by WHR and WC are $(>0.8$ and $>0.9)$ and $(>88$ and $94 \mathrm{~cm})$ for females and males respectively. Concerning body image and preference, a Standardized Stunkard Figure Rating Scale which consists of a series of nine silhouette images of women and men whose weight ranges from emaciated to morbidly obese was used. Respondents were shown individually the emaciated to morbidly obese images for them to indicate which one he or she resembles as well as the image that looks like a healthiest woman or man.

\subsection{Data Analysis}

Raw data of the study were entered into a database using Statistical Package for the Social Sciences, Inc., IL, USA (SPSS) version 20. After data entry, data cleaning and validation were done to ensure data quality before analysis. Descriptive statistics was used to determine proportions, mean, standard deviation and frequencies of interest. Cross tabulations that establish important relationships or association between dependent and independent variables were carried out using chi-square and Fisher's exact tests. Relationships between selected independent variables of respondents and prevalence of overweight/obesity were analysed using logistic regression by computing odds ratio at $95 \%$ confidence level. This enabled association between dependent and independent variables of interest to be established. A $P$-value $<.05$ was considered statistically significant whereas a $P$-value $>.05$ was not considered.

\subsection{Ethical Considerations}

Ethical approval for the study was sought and obtained from the Ghana Health Service Ethical Review Board (ID NO: GHS-ERC: 17/04/15) with the help of the University of Health and Allied Sciences, School of Public Health, Ho, Volta region. Local permission for the study was obtained from the Hohoe Municipal Health Directorate and the Hohoe Municipal Hospital as well as In-charges of health facilities and eligible participants using Informed consent form. Respondents were assured of confidentiality. They were also assured that storage, analysis and reporting of all data including dissemination will be done in formats that will not reveal their identity. After going through the Informed Consent Form, participants were made to indicate their names and signatures in the statement of consent portion of the Informed consent form to indicate their free will participation. Participant's privacy was protected especially during interview and anthropometric measurements. For example, all of the measurements such as height, weight, waist and hip circumferences were taken within their health facility in a secluded area to ensure privacy.

\section{Results}

\subsection{Background Characteristics of Respondents}

Background characteristics of respondents tested for association by sex using Chi-square and Fisher's exact tests (with $P$-values) at $95 \%$ confidence interval are shown in Table 1. There was significant association between sex of respondents and religion, age group, ethnicity, profession and parity $(P<.05)$. Female respondents were more likely to be younger than 30 years, Christians, from Ewe ethnic group, nurses and have not given birth before. However, there was no significant association between sex of respondents and marital status as well as alcohol consumption and usual time of supper $(P>.05)$. Of all respondents, nurses were more $(77.8 \%)$ than midwives $(22.2 \%)$ with strong indication that females are more likely to be nurses and midwives than males (Fisher's exact value $=.001$ ). Majority of respondents were Christians $(96.3 \% ; \mathrm{P}<.001)$, single $(48.9 \% ; \mathrm{P}=.406)$ and of the Ewe ethnic group $(77.8 \% ; \mathrm{P}=.043)$ although more than five (5) other ethnic groups of people $(22.2 \%)$ were present. Concerning age distribution, larger percentage $(51.9 \% ; \mathrm{P}=.015)$ were within the age group of $18-30$, followed by those above 50years $(22.2 \%)$ with $41-50$ year group making up $6.7 \%$ of the entire respondents. Furthermore, the prevalence of alcohol consumption among respondents was relatively low (10.4\%) but it was highest among female respondents $(8.2 \%)$ than males $(2.2 \%)$. The prevalence of nutrition related chronic diseases (comorbidities) among respondents ranged from hypertension (14.1\%), osteoarthritis $(6.4 \%)$ to type 2 diabetes (4.4\%). These diseases were interestingly not prevalent among male respondents.

\subsection{Determination of Overweight and Obesity Prevalence}

The results for the anthropometric measurements from which overweight and obesity indicators were derived are shown in Table 2. The overall mean age of respondents was 36.0 (Standard Deviation (SD) 12.6) years with mean BMI of 27.2 (SD 5.5) $\mathrm{kg} / \mathrm{m}^{2}$. There was a significant difference between mean age of male respondents and that of females ( $\mathrm{n}$ $=26,30.0(\mathrm{SD} 4.2)$ years versus $\mathrm{n}=109,37.5(\mathrm{SD} 13.5)$ years, $P=.016)$. The overall minimum age of respondents was 21 whereas the maximum was 62 years. Male respondents were significantly taller on average than their female counterparts (169.9 (SD 7.0) cm versus 159.0 (SD 6.2) $\mathrm{cm}, P<.001)$. However, females were on average more likely to be heavier and for that matter have higher BMI than males (28.0 (SD 5.6) kg/m ${ }^{2}$ versus 23.7 (SD 3.3) kg/m ${ }^{2}, P$ $<.001)$. Female respondents had on average bigger waist circumference of 88.6 (SD 13.3) $\mathrm{cm}$ as compared to 81.9 (SD $8.8) \mathrm{cm}$ in males $(P=.02)$. The mean hip circumference among female respondents was also bigger than that of male respondents (105.2 (SD 10.6) cm versus 94.9 (SD 7.1) cm, P $<.001)$ but still had lower mean WHRs than their male counterparts (0.8 (SD 0.1) and 0.9 (SD 0.1); $\mathrm{P}<.001)$ respectively.

Using the WHO cut-offs as reference, the BMI categorizations for the study population (Figure 1) shows that none of the respondents was underweight. However, the prevalence of overweight among respondents was $31.8 \%$ (6.7\% males and $25.1 \%$ females) whereas $28.9 \%$ comprising only females were obese. There was a significant association 
between gender and BMI $(\mathrm{P}<.001)$. Thus, female nurses had their male counterparts. a much greater tendency to be overweight and obese than

Table 1. Background characteristics of respondents by sex.

\begin{tabular}{|c|c|c|c|c|}
\hline Variable & Male (n=26) & Female $(n=109)$ & Total $(n=135)$ & Chi-square $\left(\chi^{2}\right), P$-value \\
\hline \multicolumn{5}{|l|}{ Age groups } \\
\hline $18-30$ & $18(69.2 \%)$ & $52(47.7 \%)$ & $70(51.9 \%)$ & $\chi^{2}=10.4, P=.02$ \\
\hline $31-40$ & $7(26.9 \%)$ & $19(17.4 \%)$ & $26(19.3 \%)$ & \\
\hline $41-50$ & $1(3.8 \%)$ & $8(7.3 \%)$ & $9(6.7 \%)$ & \\
\hline $51+$ & $0(0.0 \%)$ & $30(27.5 \%)$ & $30(22.2 \%)$ & \\
\hline \multicolumn{5}{|l|}{ Marital status } \\
\hline Married & $11(42.3 \%)$ & $48(44.0 \%)$ & $59(43.7 \%)$ & $\chi^{2}=2.9, P=.41$ \\
\hline Single & $15(57.7 \%)$ & $51(46.8 \%)$ & $66(48.9 \%)$ & \\
\hline Divorced & $0(0.0 \%)$ & $1(0.9 \%)$ & $1(0.7 \%)$ & \\
\hline Widowed & $0(0.0 \%)$ & $9(8.3 \%)$ & $9(6.7 \%)$ & \\
\hline \multicolumn{5}{|l|}{ Religion } \\
\hline Christianity & $22(84.6 \%)$ & $108(99.1 \%)$ & $130(96.3 \%)$ & $\chi^{2}=12.3 P<.001$ \\
\hline Islam & $4(15.4 \%)$ & $1(0.9 \%)$ & $5(3.7 \%)$ & \\
\hline Traditional & $0(0.0 \%)$ & $0(0.0 \%)$ & $0(0.0 \%)$ & \\
\hline \multicolumn{5}{|l|}{ Ethnicity } \\
\hline Ewe & $19(73.1 \%)$ & $86(79.9 \%)$ & $105(77.8 \%)$ & $\chi^{2}=11.5 P=.04$ \\
\hline Akan & $3(11.5 \%)$ & $6(5.5 \%)$ & $9(6.7 \%)$ & \\
\hline $\mathrm{Ga} /$ Dangbe & $0(0.0 \%$ & $5(5.6 \%)$ & $5(3.7 \%)$ & \\
\hline Guan & $1(3.8 \%)$ & $9(8.3 \%)$ & $10(7.4 \%)$ & \\
\hline Northerner & $3(11.5 \%)$ & $1(0.9)$ & $4(3.0 \%)$ & \\
\hline Others & $0(0.0 \%)$ & $2(1.8 \%)$ & $2(1.5 \%)$ & \\
\hline \multicolumn{5}{|l|}{ Profession } \\
\hline Nurse & $26(100 \%)$ & $79(72.5 \%)$ & $105(77.8 \%)$ & Fisher's exact $=.001$ \\
\hline Midwife & $0(100 \%)$ & $30(27.5 \%)$ & $30(22.2 \%)$ & \\
\hline \multicolumn{5}{|l|}{ Parity } \\
\hline 0 birth & $26(100 \%)$ & $44(40.4 \%)$ & $70(51.9 \%)$ & $\chi 2=29.9 P<.001$ \\
\hline 1 birth & $0(0.0 \%)$ & $27(24.8 \%)$ & $27(20.0 \%)$ & \\
\hline $2-4$ births & $0(0.0 \%)$ & $31(28.4 \%)$ & $31(23.0 \%)$ & \\
\hline$>4$ births & $0(0.0 \%)$ & $7(6.4 \%)$ & $7(5.2 \%)$ & \\
\hline \multicolumn{5}{|l|}{ Community type } \\
\hline Rural & $1(3.8 \%)$ & $6(5.5 \%)$ & $7(5.2 \%)$ & Fisher's exact $=1.000$ \\
\hline Urban & $25(96.2 \%)$ & $103(94.5 \%)$ & $128(94.8 \%)$ & \\
\hline \multicolumn{5}{|c|}{ Chronic disease status } \\
\hline Hypertension & $0(0.0 \%)$ & $19(17.3 \%)$ & $19(14.1 \%)$ & \\
\hline Type 2 Diabetes & $0(0.0 \%)$ & $6(5.5 \%)$ & $6(4.4 \%)$ & \\
\hline Osteoarthritis & $0(0.0 \%)$ & $7(6.4 \%)$ & $7(6.4 \%)$ & \\
\hline \multicolumn{5}{|c|}{ Alcohol consumption status } \\
\hline Yes & $3(11.5 \%)$ & $11(10.1 \%)$ & $14(10.4 \%)$ & Fisher's exact $=.733$ \\
\hline No & $23(88.5 \%)$ & $98(89.9 \%)$ & $121(89.6 \%)$ & \\
\hline $\begin{array}{l}\text { Usual supper time } \\
\text { Before } 5 \mathrm{pm}\end{array}$ & $2(7.7 \%)$ & $15(13.8 \%)$ & $43(31.9 \%)$ & \\
\hline $5-6 \mathrm{pm}$ & $5(19.2 \%)$ & $38(34.9 \%)$ & $46(34.1 \%)$ & $\chi^{2}=4.0 P=.26$ \\
\hline $6-7 \mathrm{pm}$ & $12(46.2 \%)$ & $34(31.2 \%)$ & $29(21.5 \%)$ & \\
\hline After $7 \mathrm{pm}$ & $7(26.9 \%)$ & $22(20.2 \%)$ & $17(12.6 \%)$ & \\
\hline
\end{tabular}

Table 2. Anthropometric measurements of respondents by sex.

\begin{tabular}{|c|c|c|c|c|c|c|}
\hline Variables & Male Mean (SD) & Female Mean (SD) & Total Mean (SD) & Minimum (n=135) & Maximum (n=135) & $P$-Values \\
\hline Age (yrs) & $30.0(4.2)$ & $37.5(13.5)$ & $36.0(12.6)$ & 21 & 62 & .06 \\
\hline Height $(\mathrm{cm})$ & $169.9(7.0)$ & $159.0(6.2)$ & $161.1(7.7)$ & 136.5 & 187.0 & .001 \\
\hline Weight (kg) & $68.2(8.8)$ & $70.8(14.0)$ & $70.2(13.2)$ & 42.0 & 112.7 & .37 \\
\hline BMI $\left(\mathrm{kg} / \mathrm{m}^{2}\right)$ & $23.7(3.3)$ & $28.0(5.6)$ & $27.2(5.5)$ & 18.7 & 43.5 & .001 \\
\hline $\mathrm{WC}(\mathrm{cm})$ & $81.9(8.8)$ & $88.6(13.3)$ & $87.3(12.8)$ & 63.0 & 116.0 & .02 \\
\hline $\mathrm{HC}(\mathrm{cm})$ & $94.9(7.1)$ & $105.2(10.6)$ & $103.2(10.8)$ & 81.0 & 135.0 & .001 \\
\hline WHR & $0.9(0.1)$ & $0.8(0.1)$ & $0.8(0.1)$ & 0.63 & 1.07 & .001 \\
\hline
\end{tabular}

BMI - Body Mass Index; WHR - Waist-to-Hip Ratio; WC - Waist Circumference; HC - Hip Circumference, SD - Standard Deviation 


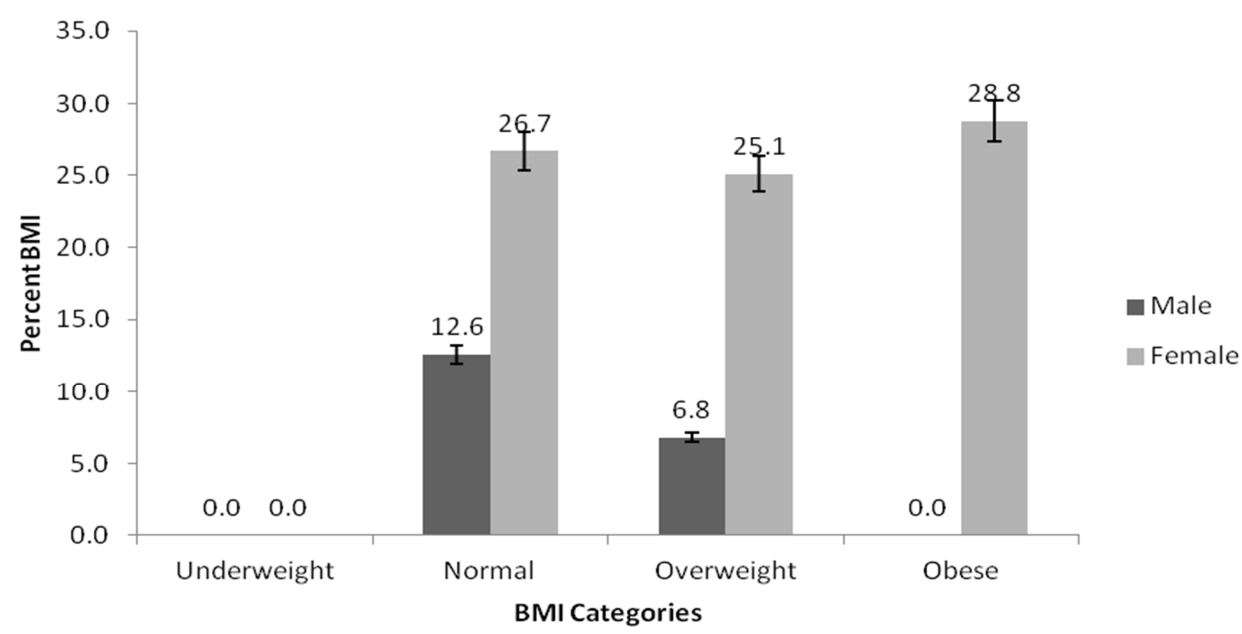

Figure 1. BMI Classification and prevalence by sex using WHO cut offs as reference. (Underweight $=<18.5 \mathrm{~kg} / \mathrm{m} 2$ ), normal $=18.5-24.99 \mathrm{~kg} / \mathrm{m} 2$ ), overweight $=25-29.99 \mathrm{~kg} / \mathrm{m} 2$ ) and obese $=\geq 30 \mathrm{~kg} / \mathrm{m} 2)$ ).

As shown in Figure 2, the prevalence of combined overweight and obesity among respondents was $60.7 \%$ whereas $39.3 \%$ had normal BMI.

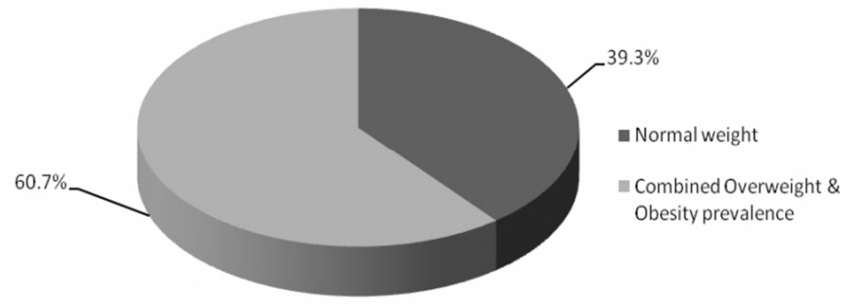

Figure 2. A pie chart showing prevalence of normal BMI and combined overweight and obesity among respondents.

Table 3 shows comparison of overweight and obesity prevalence among nurses and midwives using BMI classification. Among respondent nurses, $34.3 \%$ were overweight and $23.3 \%$ of all respondent midwives were also overweight. Prevalence of obesity among nurses was $22.0 \%$ whereas prevalence of obesity among midwives being the majority was $53.4 \%$. The overall prevalence of overweight among all respondents was $31.9 \%$ whereas that of obesity was $28.8 \%$ as indicated also in Figure 1.

Table 3. Comparison of overweight and obesity prevalence among nurses and midwives using BMI classification.

\begin{tabular}{llll}
\hline BMI Category & \multicolumn{2}{l}{ Profession of respondents } & Total \\
\hline & Nurse & Midwife & \\
\hline Normal & $46(43.8 \%)$ & $7(23.3 \%)$ & $53(39.3 \%)$ \\
Overweight & $36(34.3 \%)$ & $7(23.3 \%)$ & $43(31.9 \%)$ \\
Obese Class 1 & $17(16.2 \%)$ & $11(36.7 \%)$ & $28(20.7 \%)$ \\
Obese Class 2 & $5(4.8 \%)$ & $3(10.0 \%)$ & $8(5.9 \%)$ \\
Obese Class 3 & $1(1.0 \%)$ & $2(6.7 \%)$ & $3(2.2 \%)$ \\
Total & $105(100 \%)$ & $30(100 \%)$ & $135(100 \%)$ \\
\hline
\end{tabular}

Table 4 indicates that there was a significant difference $(P$ $=.02$ ) between the mean BMI of nurses and midwives. Thus, average BMI among midwives was higher (27.3, SD 5.4) $\mathrm{kg} / \mathrm{m}^{2}$ than that of nurses $(26.4$, SD 6.3$) \mathrm{kg} / \mathrm{m}^{2}$ though all the two means indicate a BMI status of overweight as compared with WHO's reference (overweight $=25-29.99 \mathrm{~kg} / \mathrm{m}^{2}$ ). However, there was no significant difference $(P>.05)$ between the mean WHR of nurses and midwives.

Table 4. Mean values of BMI and WHR of respondents by profession.

\begin{tabular}{lllll}
\hline \multirow{2}{*}{ Variables } & $\begin{array}{l}\text { Nurse } \\
\text { Mean (SD) }\end{array}$ & $\begin{array}{l}\text { Midwife } \\
\text { Mean (SD) }\end{array}$ & $\begin{array}{l}\text { Total } \\
\text { Mean (SD) }\end{array}$ & $\boldsymbol{P}$ - Values \\
\hline BMI $\left(\mathrm{kg} / \mathrm{m}^{2}\right)$ & $26.4(6.3)$ & $27.3(5.4)$ & $27.2(5.5)$ & .02 \\
WHR & $0.84(0.7)$ & $0.86(0.1)$ & $0.84(0.07)$ & .89 \\
\hline
\end{tabular}

Concerning central obesity, 55 (40.7\%) of respondents were considered at risk based on their WHRs as shown in Table 5. Clearly, female respondents (both nurses and midwives) were significantly more likely to be at risk for central obesity than their male counterparts as seen in the higher proportion $(42.2 \%)$ than $36.6 \%$ in males with Odds ratio of $1.37(95 \% \mathrm{CI}=0.524-3.834)$.

Table 5. Waist-to-Hip Ratio categorization of respondents by sex.

\begin{tabular}{lllll}
\hline Variables & Male & Female & Total & $\begin{array}{l}\text { Odds Ratio } \\
\text { /95\%CI }\end{array}$ \\
\hline Normal & $17(65.4 \%)$ & $63(57.8 \%)$ & $80(59.3 \%)$ & \\
At Risk & $9(36.6 \%)$ & $46(42.2 \%)$ & $55(40.7 \%)$ & $\begin{array}{l}1.37(0.524 \\
\text { Total }\end{array}$ \\
\hline
\end{tabular}

Normal ( $<0.90$ for males and $<0.85$ for females), At risk ( $>0.85$ for women and $>0.90$ for men)

Table 6 shows waist circumference of respondents by sex. Using WC to determine central or abdominal fat accumulation, $11.5 \%$ (3) of male respondents and $58.6 \%$ (53) of female respondents were both obese and therefore have higher risk of obesity-related metabolic complications as compared to $88.5 \%$ (23) males and $51.4 \%$ (56) females who were normal with a $\mathrm{p}$-value of $.006(\chi 2=11.89)$ and odds ratio of $7.3(\mathrm{CI}=1.991-39.444)$. The odds of a female nurse or midwife becoming obese (centrally), was 7.3 times higher than that of male nurses. 


\subsection{Perception and Knowledge on Overweight and Obesity}

Table 7 shows respondents' perception on body image. Results revealed that majority of respondents $(62.9 \%)$, considered themselves to be of normal weight, whereas $32.6 \%$ and $1.5 \%$ respectively said they were overweight and underweight, however, none of the respondents considered himself or herself to be obese. Nonetheless, when body image pictures (SFRS) were shown to them to indicate the image they resemble, $7.4 \%$ indicated that they were underweight, $42.2 \%$ indicated normal and $49.6 \%$ indicated overweight whereas only $0.7 \%$ indicated obese. Concerning respondents' perception of a body image that looks like a healthiest woman or man, majority, representing $60 \%$ pointed to the normal weight picture whereas the second highest (28.9\%) indicated that being overweight is healthy.

Table 6. Waist Circumference of respondents by sex.

\begin{tabular}{llllll}
\hline Variables & Male $(\mathbf{n}=\mathbf{2 6})$ & Female $(\mathbf{n}=\mathbf{1 0 9})$ & Total & Chi-square $(\boldsymbol{P}$ - value) & OR (95\% CI) \\
\hline Normal & $23(88.5 \%)$ & $56(51.4 \%)$ & $79(58.5 \%)$ & $11.89(.006)$ & 7.3 \\
At risk (Obese) & $3(11.5 \%)$ & $53(48.6 \%)$ & $56(41.5 \%)$ & $(1.991-39.444)$ & \\
Total (n) & $26(100 \%)$ & $109(100 \%)$ & $135(100 \%)$ & & \\
\hline
\end{tabular}

Normal $(<88 \mathrm{~cm}$ for females and $<102 \mathrm{~cm}$ for males), At risk $(>88 \mathrm{~cm}$ for women and $>102 \mathrm{~cm}$ for men) OR = Odds Ratio, CI $=$ Confidence Interval

Table 7. Respondents'perception on body image.

\begin{tabular}{llll}
\hline Body image variables & $\begin{array}{l}\text { What respondents considered } \\
\text { themselves to be before showing body- } \\
\text { image pictures to them }(\mathbf{n}=\mathbf{1 3 5})\end{array}$ & $\begin{array}{l}\text { Body image that respondents said they } \\
\text { resemble after body-image pictures } \\
\text { were shown to them }(\mathbf{n}=\mathbf{1 3 5})\end{array}$ & $\begin{array}{l}\text { Body-image that respondents said } \\
\text { looks like a healthiest woman or } \\
\text { man }(\mathbf{n}=\mathbf{1 3 5})\end{array}$ \\
\hline Underweight & $2(1.5 \%)$ & $10(7.4 \%)$ & $15(11.1 \%)$ \\
Normal weight & $85(62.9 \%)$ & $57(42.2 \%)$ & $81(60 \%)$ \\
Overweight & $44(32.6 \%)$ & $67(49.6 \%)$ & $39(28.9 \%)$ \\
Obese & $0(0.0 \%)$ & $1(0.7 \%)$ & $0(0.0 \%)$ \\
Do not know & $4(3.0 \%)$ & n.a & n.a \\
Total (n) & $135(100 \%)$ & $135(100 \%)$ & $135(100 \%)$ \\
\hline
\end{tabular}

n. a means not applicable

Table 8 shows that majority of respondents (34.8\%) had a good knowledge on overweight and obesity, followed by $31.1 \%$ with fair knowledge, $27.4 \%$ with a very good knowledge, whereas the least portion of respondents $(6.7 \%)$ had a low level of knowledge. The level of knowledge on overweight and obesity was a little bit higher among nurses $(62.8 \%)$ than among midwives $(60 \%)$.

Table 8. Knowledge level of respondents on overweight and obesity by profession.

\begin{tabular}{llll}
\hline $\begin{array}{l}\text { Knowledge } \\
\text { level }\end{array}$ & Nurse $(\mathbf{n}=\mathbf{1 0 5})$ & Midwife $(\mathbf{n}=\mathbf{3 0})$ & Total $(\mathbf{n}=\mathbf{1 3 5})$ \\
\hline Very good & $31(29.5 \%)$ & $6(20.0 \%)$ & $37(27.4 \%)$ \\
Good & $35(33.3 \%)$ & $12(40.0 \%)$ & $47(34.8 \%)$ \\
Fair & $34(32.4 \%)$ & $8(26.7 \%)$ & $42(31.1 \%)$ \\
Low & $5(4.8 \%)$ & $4(13.3 \%)$ & $9(6.7 \%)$ \\
Total $(\mathrm{n})$ & $105(100 \%)$ & $30(100 \%)$ & $135(100 \%)$ \\
\hline
\end{tabular}

\subsection{Assessment of Risk Factors Contributing to Overweight and Obesity}

Table 9 indicates that higher proportion of respondents $(57.3 \%)$ who did not exercise or had low physical activity level were overweight as compared to those who exercised more than 3 hours per week (3.7\%). This showed a significant association between being sedentary and subsequently becoming overweight $(P<.001)$.
Table 9. Comparison of BMI status and physical activity (exercise) levels.

\begin{tabular}{|c|c|c|c|}
\hline \multirow{2}{*}{$\begin{array}{l}\text { Physical activity } \\
\text { level }\end{array}$} & \multicolumn{2}{|l|}{ BMI status } & \multirow{2}{*}{$\begin{array}{l}\text { Fisher's exact } \\
\text { (p-value) }\end{array}$} \\
\hline & $\begin{array}{l}\text { Not Overweight } \\
(\mathrm{n}=53)\end{array}$ & $\begin{array}{l}\text { Overweight } \\
(n=82)\end{array}$ & \\
\hline No exercise & $14(26.4 \%)$ & $47(57.3 \%)$ & \multirow{5}{*}{$18.65(.001)$} \\
\hline$<1$ hour/week & $9(17.0 \%)$ & $16(19.5 \%)$ & \\
\hline 1-2 hours/week & $13(24.5 \%)$ & $12(14.6 \%)$ & \\
\hline 2-3 hours/week & $8(15.1 \%)$ & $4(4.9 \%)$ & \\
\hline$>3$ hours/week & $9(17.0 \%)$ & $3(3.7 \%)$ & \\
\hline
\end{tabular}

Figure 3 shows that mean BMI values of respondents who had either no or low physical activity levels were high in the range of $26.3-29.1 \mathrm{~kg} / \mathrm{m}^{2}$ which indicate BMI status of overweight. However, respondents whose activity level was either high or moderate had normal BMI status of 23.1 $24.3 \mathrm{~kg} / \mathrm{m}^{2}$ respectively which is within the range of WHO's normal BMI reference value (normal $=18.5-24.99 \mathrm{~kg} / \mathrm{m}^{2}$ ). This finding indicates also showed a significant association between physical activity levels and BMI status $(\mathrm{P}<.001$ at 95\% CI) as shown in Table 9.

Table 10 shows that there was a higher proportion of midwives $(76.7 \%)$ who were overweight as compared to $56.2 \%$ of nurses who were overweight. Moreover, the odds of a midwife becoming overweight was 0.4 times higher as compared to a nurse $(\mathrm{OR}=0.4, \mathrm{CI}=0.1306-1.0513, \mathrm{P}$ $=.043)$. Thus, midwives have higher chance of becoming overweight or obese than nurses. 


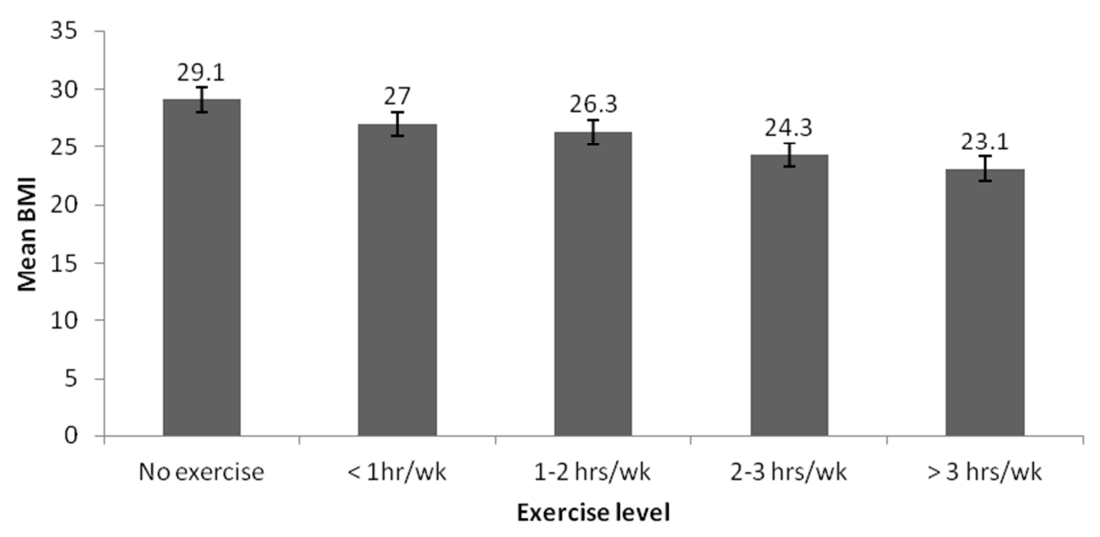

Figure 3. Mean BMI status of respondents according to their physical activity levels.

Table 10. Assessing the risk of becoming overweight by profession.

\begin{tabular}{llllll}
\hline BMI status & Profession & & & Chi-square (P-value) & Odds Ratio (95\% CI) \\
\hline & Nurse & Midwife & Total & & $4.10(.04)$ \\
\hline Not Overweight & $46(43.8 \%)$ & $7(23.3 \%)$ & $53(39.3 \%)$ & & $0.4(0.1306-1.0513)$ \\
Overweight & $59(56.2 \%)$ & $23(76.7 \%)$ & $82(60.7 \%)$ & & \\
Total (n) & $105(100 \%)$ & $30(100 \%)$ & $135(100 \%)$ & & \\
\hline
\end{tabular}

Table 11 shows that risk factors that contribute to overweight and obesity among respondents included advanced age $(41-50$ years and 51 years and more with significant $P$ values of .02 and .001 respectively). Marital status (widowed) was also shown to have positive association with overweight and obesity $(P=.004)$. Likewise, parity of more than four (4) births was shown to be associated with overweight and obesity $(P=.04)$ as well as late supper $(6$ $7 \mathrm{pm}$ and after $7 \mathrm{pm})$ were positively associated with the dependent outcome $(P=.014$ and $P=.010)$ respectively.

Table 11. Assessment of factors contributing to overweight and obesity.

\begin{tabular}{llllll}
\hline Variables & \multirow{2}{*}{ Coefficient } & $\begin{array}{l}\text { Std. } \\
\text { Error }\end{array}$ & $\boldsymbol{P}$-value & \multicolumn{2}{c}{$\mathbf{9 5 \%}$ Conf. Interval } \\
\hline Age group & & & & Lower & Upper \\
$31-40$ & 1.75225 & 1.22661 & .16 & -0.6764 & 4.18085 \\
$41-50$ & 4.69729 & 2.0262 & .02 & 0.68555 & 8.70903 \\
$51+$ & 5.49393 & 1.65783 & .001 & 2.21154 & 8.77632 \\
Marital status & & & & & \\
Single & -0.5264 & 0.98246 & .59 & -2.4716 & 1.41879 \\
Divorced & -1.0792 & 4.6016 & .82 & -10.19 & 8.03165 \\
Widowed & -5.1266 & 1.74607 & .004 & -8.5837 & -1.6695 \\
Parity & & & & & \\
1 birth & 0.68451 & 1.28083 & .59 & -1.8514 & 3.22046 \\
2-4 births & 1.79107 & 1.72593 & .30 & -1.6262 & 5.20828 \\
> 4 births & 5.14104 & 2.44808 & .04 & 0.29402 & 9.98806 \\
Usual supper time & & & & \\
6-7pm & 3.24541 & 1.30282 & .014 & 0.66592 & 5.82491 \\
After 7pm & 3.58736 & 1.37264 & .010 & 0.86963 & 6.3051 \\
\hline
\end{tabular}

\section{Discussion}

\subsection{Prevalence of Overweight and Obesity}

The purpose of this study was to assess the prevalence and potential determinants of overweight and obesity among practicing nurses and midwives in the Hohoe Municipality of the Volta region of Ghana. Concerning age distribution, larger percentage $(51.9 \%, P=.02)$ were within the age group of $18-30$, followed by those above 50 years $(22.2 \%)$ and 41 - 50 year group making up $6.7 \%$ of the entire respondents. This may imply that the Hohoe Municipality in terms of health service delivery may have a challenge of about $22.2 \%$ attrition of both nurses and midwives due to retirement in the next few years. Likewise, the relatively larger number $(22.2 \%)$ of respondents above 51 years and above over the middle aged nurses could probably be explained by the retention of older and more experienced staff (especially midwives) or the preference of older nurses to remain in the big health facilities as they reach their retirement age as revealed in the study conducted by Aryee et al. [11]. Results of this study showed that there was no underweight among the study sample $(n=135)$ which may not support the idea of the existence and persistence of the phenomenon described as a "double burden" of disease, which is common in many developing countries [4, 11]. However, the study indicated that $39.3 \%$ of the respondents had normal BMI $(12.6 \%$ males and $26.7 \%$ females); overweight among respondents was $31.8 \%$ (6.7\% males and $25.1 \%$ females) whereas $28.9 \%$ comprising only females were obese. The comparatively higher prevalence of overweight and obesity in this study population to that of the general Ghanaian population, according to the GDHS (21\% and 9\%) [9] and that of nurses in the Tamale Metropolis by Aryee et al. (26.4\% and $16.9 \%)$, [11] may be explained by a possibly higher socio-economic status in the study population compared to the average Ghanaian population or perhaps because the study population is largely female dominated, as these characteristics have been known to be associated with overweight and obesity [15]. The study findings are also consistent with other studies $[6,8]$ which reported prevalence of overweight and obesity of public health significance among nurses in Nigeria and the 
USA respectively. Nonetheless, the levels in the two studies cited were much higher perhaps because the USA study for instance, reflected the very high levels of overweight and obesity in the American population and for that matter the female population, whilst in the Nigerian study this could be attributed to the use of female subjects only for the study.

The use of WHR for central obesity [16], has also demonstrated that female nurses and midwives in this study are at a higher risk of chronic diseases such as hypertension, diabetes and arteriosclerosis than their male counterparts $(42.2 \%$ and $36.6 \%$ respectively, $\mathrm{OR}=1.37, \mathrm{CI}=0.524$ 3.834). This finding agrees with that of Azadbakht et al. who reported high prevalence of central obesity in Iranian women compared to men and also depicted their risk for such chronic diseases [17]. Furthermore, the use of WC that revealed central or abdominal fat accumulation prevalence of $41.5 \%$ $(\chi 2=11.89, \mathrm{P}=.006, \mathrm{OR}=7.3, \mathrm{CI}=1.991-39.444)$ among this study population implies increased risk of obesity-related metabolic complications which gives credence to data from a random sample of 2,183 men and 2,698 women aged 20-59 years from the Netherlands. The pattern of body fat distribution as measured by WHR and WC has been reported to be a more important determinant of chronic diseases than general obesity [1]. The essence of the finding in this study of overweight and obesity prevalence that can be compared to those of developed countries, coupled with the rates at which such countries are experiencing the fall outs from this epidemic, in terms of rising NCDs, may buttress the important point of Ogunjimi et al. that if corrective measures are not put in place, our care providers sooner than later would become care receivers [6].

\subsection{Body Image, Knowledge and Perception on Overweight and Obesity}

Majority of respondents $(62.9 \%)$, considered themselves to be of normal weight, whereas $32.6 \%$ and $1.5 \%$ respectively said they were overweight and underweight. None of the respondents considered himself or herself to be obese. However, when body image pictures (SFRS) were shown to respondents to indicate the image they resemble, 7.4\% indicated that they were underweight, $42.2 \%$ indicated normal weight and $49.6 \%$ indicated overweight whereas only $0.7 \%$ indicated obese. Concerning respondents' perception of a body image that looks like a healthiest woman or man, majority, representing $60 \%$ pointed to the normal weight picture whereas the second highest $(28.9 \%)$ indicated that being overweight is healthy as it has been established by Duda et al. [18]. The study also revealed that majority of respondents $(34.8 \%)$ had a good knowledge on overweight and obesity, followed by $31.1 \%$ with fair knowledge, $27.4 \%$ with a very good knowledge, whereas the least portion of respondents $(6.7 \%)$ had a low level of knowledge. The level of knowledge on overweight and obesity was a little bit higher among nurses $(62.8 \%)$ than among midwives $(60 \%)$. This assertion might have contributed to the higher prevalence of overweight and obesity among midwives than nurses as indicated in Table 10.

\subsection{Risk Factors Contributing to Overweight and Obesity in the Study Population}

It has been established that socio-demographic and socioeconomic statuses are related to overweight and obesity in many populations [15]. Likewise, this study found that there were significant associations between age, gender, marital status as well as parity and overweight or obesity. First, female gender was identified as a significant risk factor for overweight and obesity $(\chi 2=11.89, P=.006, \mathrm{OR}=7.3, \mathrm{CI}=$ 1.991 - 39.444) which conforms to the general trend for gender relationships with BMI in several other studies. For instance, studies from developing countries including Ghana have shown that obesity is more common in women than men [11]. Secondly, increase in age above 41 years was identified as a risk factor for overweight and obesity in this study $(P<.001)$. Marital status (widowed) was also shown to have positive association with overweight and obesity $(P$ $=.004)$. Likewise, parity of more than four (4) births was shown to be associated with overweight and obesity $(P=.04)$.

Many studies have shown that unhealthy lifestyle behaviours, particularly lack of exercise which invariably leads to low physical activity contribute significantly to overweight and obese tendencies [1,11]. This existing knowledge supports the findings this study obtained that physical inactivity (no or low exercise levels) was positively associated with the dependent outcome $(\mathrm{P}<.001)$. Dietary habits such as usually eating late beyond $6 \mathrm{pm}$ and low fruit and vegetable intake were also positively associated with overweight and obesity $(P=.010)$.

\section{Conclusion}

Results from this study have shown that prevalence of overweight and obesity was high among nurses and midwives in the Hohoe Municipality of the Volta region of Ghana. This was associated with socio-demographic and economic characteristics such as age, gender, marital status, parity and profession. A predominance of physical inactivity and dietary habit of eating too late in the night were found to be significant contributors to overweight and obesity among respondents. This was due to respondents' occupation and various sedentary tendencies associated with their job thus posing a significant risk of becoming overweight and obese as well as developing central obesity which may have serious consequences on their health and performance within the health service.

\section{Recommendations}

1. We recommend that the findings of this study should be used by local health authorities (Hohoe Municipal Health Directorate and the Hohoe Municipal Hospital) for planning, implementing and monitoring the effectiveness of local programmes for the prevention and control of overweight and obesity among health workers especially nurses and midwives in the Hohoe 
Municipality and beyond. These programmes can focus on the factors found to be significantly associated with overweight and obesity in this study and findings in other studies. These measures include wellness and fitness programmes (health walk, jogging, gymnasium, soccer, including creating opportunity for physical activities by expanding existing health facilities such as the physiotherapy unit to benefit more staff) as part of reviving nutrition and regenerative health programme to increase physical activity.

2. Local health authorities should make sure that healthy diet/dietary modification education campaign is carried out continuously in the Hohoe Municipality to enable staff adopt long-term behaviour change and more indepth understanding of individual, interpersonal, organizational and community factors that affect this behaviour in the context of different ethnicity and culture.

\section{Authors' Contributions}

CD conceived the study and financed the study, collected data, entered data, analysed data and wrote report; TKA and PA also participated in data collection, data entry, analysis and discussion; FBZ supervised and provided direction for the study, reviewed study report for submission and publication; $\mathrm{CD}$ also finalized the revision of the paper for submission and subsequent follow-up to get the paper published. All authors approved the revised manuscript.

\section{Acknowledgement}

The authors wish to express our profound gratitude to the Almighty God for His incessant protection, knowledge and life given us to produce this work.

Our appreciation also goes to all Faculty members of the School of Public Health - Hohoe, UHAS, especially, Mr. Wisdom Kwami Takramah for their direction and support.

We would like to thank the Management of the Hohoe Municipal Health Directorate especially Dr. Felix Doe, Mr. McLlinus Djata and Ms. Gift Asempa as well as the Management of the Hohoe Municipal Hospital, particularly; Dr. Pius Mensah, Mr. Emmanuel Aforbu and Madam Patricia Azumatse, for their immense support and guidance accorded us in this study.

May the Almighty God richly bless and replenish in many folds whatever you have lost for the sake of this study.

\section{References}

[1] Chan, R. S. M. \& Woo, J. (2010). International Journal of Environmental Research and Public Health: Prevention of Overweight and Obesity: How Effective is the Current Public Health Approach. 7, 765-783; doi: 10.3390/ijerph7030765.

[2] World Health Organization (2014). Fact sheet No. 311: obesity and overweight. http://www.who.int/mediacentre/factsheets/fs311/en/ (Accessed: 5th September, 2014).
[3] Global Burden of Disease, Lancet, 2014, Global, regional, and national prevalence of overweight and obesity in children and adults during 1980-2013: a systematic analysis for the Global Burden of Disease Study 2013. http://dx.doi.org/10.1016/S0140-6736 (14)60460-8.

[4] Abubakari, A. R., Lauder, W., Agyemang, C., Jones, M., Kirk, A. and Bhopal, R. S. (2008) Prevalence and time trends in obesity among adult West African populations; a metaanalysis. Obes Rev; 9(4): 297-311.

[5] Christensen, R., Bartels, E. M., Astrup, A. and Bliddal, H. (2007). Effect of weight reduction in obese patients diagnosed with knee osteoarthritis: a systematic review and metaanalysis. Ann. Rheum. Dis. 66, 433-439.

[6] Ogunjimi, L. O., Ikorok, M. M. and Olayinka, Y. O. (2010). Prevalence of obesity among Nigeria nurses: The Akwa Ibom state experience. International NGO Journal vol5 (2), pp.045049 .

[7] Chukwuonye, I. I., Chuku, A., John, C., Ohagwu, K. A., Imoh, M. E., Isah, S. E., et al. (2013). Prevalence of overweight and obesity in adult Nigerians - a systematic review. Diabetes, Metabolic Syndrome and Obesity: Targets and Therapy. http://dx.doi.org/10.2147/DMSO.S38626.

[8] Miller S. K., Alpert P. T. and Cross C. L. (2008). Overweight and obesity in nurses, advanced practice nurses, and nurse educators. J Am Acad Nurse Pract. 20(5): 259-65.

[9] Ghana Statistical Service (GSS), Ghana Health Service (GHS), and ICF Macro. 2009. Ghana Demographic and Health Survey 2008: Key Findings. Calverton, Maryland, USA: GSS, GHS, and ICF Macro.

[10] Aryeetey, R and Ansong, J. (2011) Overweight and hypertension among college of health sciences employees in Ghana. African Journal of Food, Agriculture, Nutrition and Development, Vol. 11, No. 6.

[11] Aryee, P. A., Helegbe, G. K., Baah, J., Sarfo-Asante, R. A. and Quist-Therson, R. (2013) Prevalence and Risk Factors for Overweight and Obesity among Nurses in the Tamale Metropolis of Ghana. Journal of Medical and Biomedical $\begin{array}{llll}\text { Sciences } & 2(4) \text { : } & 13-23 . & \text { doi: }\end{array}$ http://dx.doi.org/10.4314/jmbs.v2i4.3.

[12] Wang, Y .C, McPherson, K., Marsh T., Gortmaker, S. L., (2011) Brown M. Health and economic burden of the projected obesity trends in the USA and the UK. Lancet. 378: 81525 .

[13] Despres, J. P. (2006). Is visceral obesity the cause of the metabolic syndrome? Annals of Medicine; 38: 52-63.

[14] Snijder, M. B., van Dam, R. M., Visser, M., Seidell, J. C. (2006). What aspects of body fat are particularly hazardous and how do we measure them? International Journal of Epidemiology; 35: 83-92.

[15] Benkeser R. M., Biritwum R and Hill A. G (2012). Prevalence of overweight and obesity and perception of healthy and desirable body size in urban, Ghanaian women. Ghana Medical Journal vol. 46 No 2, 66-75.

[16] Vazquez, G., Duval, S., Jacobs, D.R., Jr. and Silventoinen, K. (2007). Comparison of body mass index, waist circumference, and waist/hip ratio in predicting incident diabetes: a metaanalysis. Epidemiologic Rev. 29, 115-128. 
[17] Azadbakht L, Mirmiran P. and Shiva N. (2005); General obesity and central adiposity in a Representative Sample of Tehranian Adults: Prevalence and Determinants; Int J Vitam Nutr Res 75, 297-304.
[18] Duda, R. B., Dark, R., Seffah, J., Adanu, R. M. K., Anarfi, J. K. and Hill, A.G. (2007). Prevalence of Obesity in Women of Accra, Ghana. African Journal of Health Sciences; 14: 154159. 